\title{
Technology Enabled Manufacturing Industry Practices - Industry 4.0
}

\author{
M. Uthayakumar, Irfan Haneef, M. Adam Khan, M.T.H. Sultan
}

\begin{abstract}
The main aim of this research is to identify the scope for matured and emerging technologies to improve the quality, productivity, energy efficiency and sustainability. Industry 4.0 encourages the manufacturing industries to embrace conducive technologies. The paradigm shifts with OEMs manufacturing quality levels naturally elevate the expectations from the supplier industries. This demands more from the technology and $R \& D$ firms to deliver. Simulation technologies are becoming vital part of the industry practices. Augmented Reality and Virtual Reality based simulations are being analyzed here with its utility in manufacturing industries.
\end{abstract}

Keywords : AR, VR, MR, XR, Simulation, Industry 4.0.

\section{INTRODUCTION}

Industry 4.0 (I4.0) is the term used to represent fourth Industrial revolution happening with the assistance of technologies. Smart factories are part of I4.0where machines are augmented with web connectivity and connected to a system that can visualize the entire production chain and make decisions on its own. Market requirement, design, development, validation, pilot production, planning, series production, quality control, logistics data management and aftersales support all these processes will gain momentum in I4.0. Training and skill development is a major focus in Industry to improve competitiveness, productivity, quality and safety. Broadly this can be named training digitalization which include soft skills, hard skills and knowledge training.

\section{CHARACTERESTICS OF I4.0}

\section{A. Interconnection}

The units at far locations will be interconnected for the operations and operate on an optimized way aligning to lean manufacturing.

\section{B. Data Transparency}

Data and information will be automatically captured and shared selectively to the needed stations with access controls. The possibility of errors is reduced to very low.

Revised Manuscript Received on December 29, 2019.

* Correspondence Author

M. Uthayakumar*, Faculty of Mechanical Engineering, Kalasalingam Academy of Research and Education, Srivilliputhur, India. Email: m.uthayakumar@klu.ac.in

S. Vigneshwaran, Faculty of Mechanical Engineering, Kalasalingam Academy of Research and Education, Srivilliputhur, India.

M. Adam Khan, Faculty of Mechanical Engineering, Kalasalingam Academy of Research and Education, Srivilliputhur, India.

M.T.H. Sultan, Department of Aerospace Engineering, Universiti Putra Malaysia, Malaysia

\section{Technology Assistance}

Various centers of design, manufacturing or services will be assisted with technologies which will have product life cycle management.

\section{Decentralized Decisions}

Each operating station do decision making by the cyber physical systems on their own and perform their tasks as autonomously as possible. In the case of exceptions, or conflicts tasks are delegated to a higher level.

\section{TECHNOLOGIES FOR I4.0}

The digital technologies that will be assisting I4.0 are predominantly the following.

1. Simulations -Augmented reality/Virtual Reality (AR/VR)

2. Internet of Things (IoT) platforms

3. Mobile devices

4. Global Positioning Systems

5. Authentication Detection

6. Additive Manufacturing

7. Smart sensors

8. Big data analytics

9. Block-chain

10. Artificial Intelligence

11. Cloud computing

Out of these, simulation technologies Augmented Reality (AR) and Virtual Reality (VR) are chosen to discuss in detail.

\section{AR/VR}

Digitalization is one of the most key technique in industry 4.0. Simulation is recreation of real life environment or situation. AR / VR are two major technologies used for industry simulation. By 2022 , industry sector is expected to spend $27 \%$ on AR/VR solutions [1].

Augmented reality (AR) is a technology that layers computer-generated enhancements atop an existing reality in order to make it more meaningful through the ability to interact with it. AR is developed into applications and used on mobile devices to blend digital components into the real world in such a way that they enhance one another, but can also be told apart easily. AR is used with holograms and motion activated commands.

Virtual reality (VR) is an artificial, computer-generated simulation that immerses the user by making them feel like they are experiencing the simulated reality firsthand, primarily by stimulating their vision and hearing. 
Virtual reality is possible through a coding language known as VRML (Virtual Reality Modeling Language). VR is typically achieved by wearing a headset with the technology. Figure 1 shows the VR application in the industry.

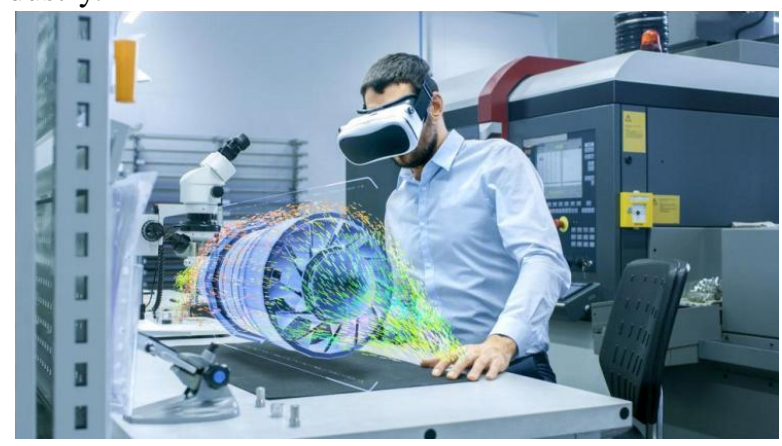

Figure 1. Simulation in Industry [2]

\section{SIMULATION IN TRAINING}

Simulation technology is used to create and enhance an imaginary reality for gaming, entertainment, and play. It can enhance training for real life environments by creating a simulation of reality where people can practice beforehand. Flight, welding, driving are a few examples of practical training where AR/VR simulation techniques are used. The guidelines for choosing the technology can be represented as below.

Understnd Context and User's intention $\rightarrow$ Identify the right service $\rightarrow$ Choose the best local devices [1]

\section{TRAINING}

Skill training is vital for the manufacturing industries. Two types of skills are cognitive and dexterity.

\section{A. Cognitive training}

Cognitive training is a program of regular mental activities purported to maintain or improve one's cognitive abilities. It is also called brain training. It reflects a hypothesis that cognitive abilities can be maintained or improved by exercising the brain. It is more in to mental training through thinking, puzzling and gaming. Cognitive methods are used in industries to learn machine operations, settings changes, safety procedures.

\section{B. Dexterity}

The coordination of small muscles, in movements usually involving the synchronization of hands and fingers with the eyes is called dexterity. This is also known as fine motor skills. The complex levels of manual dexterity that humans exhibit can be attributed to and demonstrated in tasks controlled by the nervous system. This study will investigate more in to dexterity skills for the manufacturing sector.

\section{Dexterity Skills in Manufacturing}

Welding, brazing, soldering, spray painting is a few commonly required dexterity skills in manufacturing sector. Improper skill sets can affect the productivity, wastages of consumables, quality rejections, reworks, product aesthetics, work hazards. To address these issues industries, plan skill auditing, training and recertification of the workforce in the critical areas. The conventional training methods were generally followed across the industry sectors which has following challenges

1. Non-uniform training methods

2. More dependent on trainer skills and knowledge

3. Wastages of consumables

4. More preparation time and thereby less practicing time

5. Difficult and time consuming to map skill gap Vs quality defects

6. A wrong practice is almost impossible to revert.

\section{Modernization in dexterity skills}

The advancement in technology is utilized for skill training to overcome the challenges briefed above.

Simulation implies an imitation of a real-life process, usually via a computer or other technological device, to provide a lifelike experience. This has proven to be a reliable and successful method of training in thousands of industries worldwide. They can be used both to allow specialization in a certain area, and to educate individuals in the workings of the sectors as a whole. Simulation methods are getting more acceptance as it makes the learning more entertaining, systematic and independent.

\section{WELDING TRAINING SIMUALTION}

Welding is a metal joining manufacturing process. AR / VR technologies are used to simulate the welding process to train the work force. Figure 1 shows the VR application in the welding simulation training. Use of simulation methods in welding training has got following advantages

1. Live feedback

2. Self-learning

3. Very less time for job preparation and more time for practice

4. Independent of trainer's skills

5. Tracking of practice sessions

6. Fast switching between welding processes, materials, wire diameters, mechanical parameters and compositions

7. Replay of the practice sessions

8. Complex work pieces can be practiced at difficult positions and orientations

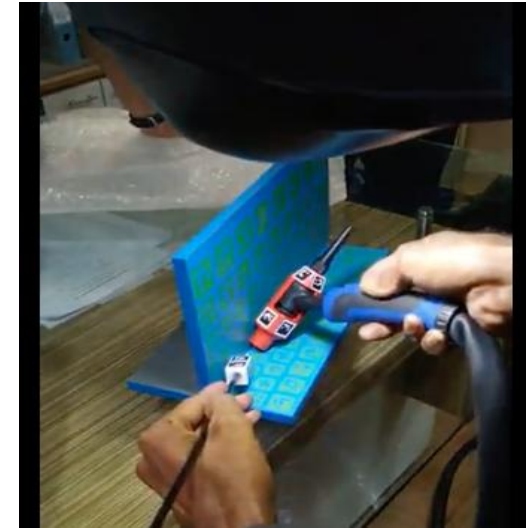

Figure 2 Practice on TIG Welding Simulator 


\section{SIMUALTION PRINCIPLES}

Welding skill training demands, the following parameters visualization and feedback on priority

1. CTWD - Contact to Work Distance. This is the distance between the work piece and the welding torch tip. Maintaining an optimum gap is very important for the weld performance. This affects the weld strength and spatters.

2. Angles - Work angle and travel angle are to be maintained during welding.

3. Speed of the weld is important for the weld strength and material deposition

These technical parameters are to be monitored and alert the user to maintain the correct values.

\section{SIMULATION AND ROBOTICS}

Robotics and automation are one of the key elements of industry 4.0. The simulation techniques can be used to optimize the parameters to be flashed in to the automated system. Number of iterations to find the optimal settings can be done through simulation. Simulators can be used to train the operators in robotic welding.

\section{CONCLUSION}

The technologies are going to increase its stake in manufacturing industries from field to factories. The intelligence in choosing the right technology for the right digitalization is going to be the game-changer. Digitalization needs education.

\section{REFERENCES}

1. "Challenges for massive adoption of AR/VR in industry 4.0" - David Maurange, Yoann Yvon, 2018

2. "5 Important Augmented and Virtual Reality Trends" - Bernard Marr; Forbes.com Jan 14, 2019

\section{AUTHORS PROFILE}

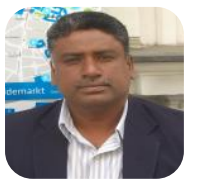

Dr. M. Uthayakumar has obtained Master of Engineering in Production Engineering from Thiagarajar College of Engineering (Autonomous), Madurai, India and Doctorate from Department of Production Engineering, National Institute of Technology, Tiruchirappalli. He has published 145 papers in the international journals and conference. Currently he is a Professor at Department of Mechanical Engineering, Kalasalingam Academy of Research and Education, Krishnankoil, Virudhunagar Dist.

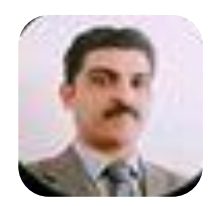

Irfan Haneef is the Director in AMFA MECH LLP, doing technology projects with manufacturing industries. He has obtained Master of Technology in Automotive Technology from Indian Institute of Technology Madras. His Bachelor Degree is in Mechanical Engineering from TKM College of Engineering, Kollam. He is presently doing part-time research in Kalasalingam Academy of Research and Education, India. His area of interest includes welding and similar manufacturing methods.

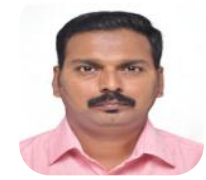

Dr. M. Adam Khan is a Post-Doctoral Researcher from the Department of Mechanical and Industrial Engineering Technology, University of Johannesburg, South Africa. He received his Doctoral Degree from National Institute of Technology, Tiruchirappalli, India. His Bachelor (B.E.) and Master Degree (M.E.) from Anna University, Chennai in the specialization of Production and Design. His research focused on surface engineering and metallurgical analysis on processed materials. He has published 38 technical articles in different journals of international repute. 